\title{
Cadmium and Lead Removal from Aqueous Solution by Grape Stalk Wastes: Modeling of a Fixed-Bed Column
}

\author{
Nuria Miralles, César Valderrama,* Ignasi Casas, María Martínez, and Antonio Florido \\ Departament d'Enginyeria Química, ETSEIB, Universitat Politècnica de Catalunya, 08028 Barcelona, Spain
}

\begin{abstract}
Grape stalk wastes generated in the wine production process were used for the removal of cadmium and lead ions from aqueous solutions. The experimental breakthrough curves (BTC) were obtained from fixedbed columns. Experiments were carried out to evaluate the influence of both inlet metal concentration and sorbent particle size. The experimental data were fitted to the Thomas model, a well-established fixed-bed sorption model. The theoretical sorption capacities obtained by the Thomas model were in good agreement with the breakthrough capacities determined from the sorption data. The CXTFIT code was used to determine the transport and sorption parameters of the convective-dispersive equation (CDE) and the two-site deterministic nonequilibrium (TSM/CDE) model by adjusting the models to the experimental breakthrough curves. The results showed that sorption capacities as well as both transport and sorption parameters were affected by the initial metal concentration as well as by the sorbent particle size.
\end{abstract}

\section{Introduction}

The presence of heavy metals like cadmium and lead in industrial wastewater and effluents is of great concern due to their high toxicity and adverse accumulation characteristics. ${ }^{1-3}$ Considering the harmful effects of heavy metals, it is necessary to remove them from liquid wastes at least to the limit accepted by regulations. ${ }^{4}$ Several technologies have been used for the removal of metals from waste discharges, which include chemical precipitation, coagulation/flocculation, ion exchange/solvent extraction, cementation, complexation, electrochemical operations, biological operations, adsorption, evaporation, filtration, and membrane processes. ${ }^{5,6}$ Sorption processes, including ion exchange and adsorption, are an alternative with great potential to treat water and wastewaters containing heavy metals. ${ }^{7}$ The main disadvantage of the sorption method is the high price of the adsorbents, which increases the price of wastewater treatment. Therefore, it is important to search for cheaper adsorbents that may be used in the treatment of wastewater containing heavy metals. ${ }^{6,8}$ The ability of biological materials to retain metal ions has received considerable attention for the development of an efficient, clean, and cheap technology for wastewater treatment. ${ }^{9}$ One of these sorbents is grape stalk wastes generated in the wine production process, which has been satisfactorily applied in batch studies of copper and nickel, ${ }^{10,11}$ lead and cadmium, ${ }^{12}$ and chromium removal, ${ }^{13}$ previous studies demonstrate that grape stalks are a prominent sorbent for nickel and copper removal in a fixed bed column. ${ }^{14,15}$ In these works, sorption of metal ions onto grape stalks released an equivalent amount of alkaline and alkaline earth metals $\left(\mathrm{K}^{+}, \mathrm{Mg}^{2+}\right.$, and $\left.\mathrm{Ca}^{2+}\right)$ as well as protons, indicating that ionic exchange is the predominant process responsible for metal ion uptake. ${ }^{10,12}$ Both batch and kinetic experiments showed sorption uptake to have a $\mathrm{pH}$-dependent profile, with a maximum metal sorption recovery at around $\mathrm{pH}$ 4.5 and 6.5 for lead and cadmium, respectively. ${ }^{12}$

* Corresponding author. E-mail: cesar.alberto.valderrama@upc.edu. Tel.: +34 93 4011818. Fax: +34 9340158 14. Departament d'Enginyeria Química, Universitat Politècnica de Catalunya, Av. Diagonal 647, Edifici H Planta 4a, Barcelona 08028 Spain.
Batch experiments are used to obtain equilibrium sorption isotherms and to evaluate the sorption capacity of sorbents for given metals present in fluid phases. ${ }^{16}$ However, in the practical operation of full-scale biosorption processes, continuous-flow fixed-bed columns are often preferred. In such systems, the concentration profiles in the liquid and sorbent phases vary in both space and time. ${ }^{9,17}$ As a result, it is difficult to carry out a priori design and optimization of fixed-bed columns without a quantitative approach. From the perspective of process modeling, the dynamic behavior of a fixed-bed column is described in terms of the breakthrough curve. ${ }^{18}$

The objective of the present study is the recovery of $\mathrm{Pb}(\mathrm{II})$ and $\mathrm{Cd}(\mathrm{II})$ from aqueous solutions by using grape stalk wastes in a fixed bed column. For this purpose, the CXTFIT code ${ }^{19}$ was used to estimate the transport and sorption parameters of the convectivedispersive equation (CDE) and the two-site deterministic nonequilibrium (TSM/CDE) models by adjusting the models to the experimental breakthrough curves (BTC). Additionally, a wellestablished fixed-bed sorption model (Thomas) was used to determine the theoretical sorption capacity and to compare it to the breakthrough capacity determined by the column experimental data. The influence of the inlet concentration and the particle size effect were evaluated for both metals.

\section{Experimental Section}

Materials. Grape stalk wastes, generated in the wine production process (supplied by a wine manufacturer of the Empordà-Costa Brava region, Girona, Spain), were rinsed three times with deionized water, dried in an oven at $110{ }^{\circ} \mathrm{C}$ until constant weight, and finally cut and sieved to four particle sizes ranging from $(0.35$ to 1.4$) \mathrm{mm}$. The properties of the sorbents are listed in Table 1. Metal solutions were prepared by dissolving appropriate amounts of $\mathrm{Pb}\left(\mathrm{NO}_{3}\right)_{2}$ (s) and $\mathrm{Cd}\left(\mathrm{NO}_{3}\right)_{2} \cdot 4 \mathrm{H}_{2} \mathrm{O}(\mathrm{s})$ in deionized water (Milli-Q system). All reagents were analytical grade and were purchased from Panreac (Barcelona, Spain). Metal standard solutions of 1000 $\mathrm{mg} \cdot \mathrm{L}^{-1}$ purchased from Carlo Erba (Milano, Italy) were used for Flame Atomic Absorption Spectroscopy (FAAS). Nitrate tracer 
Table 1. Physical and Chemical Properties of Grape Stalk Wastes

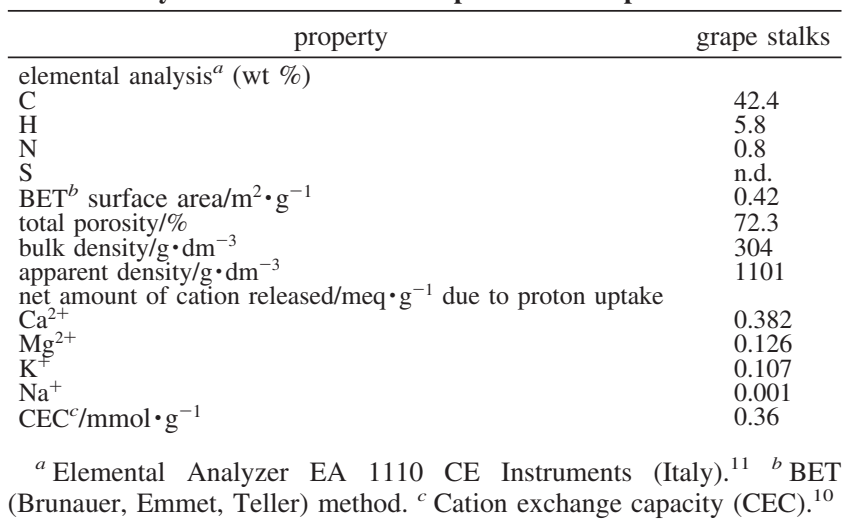

solutions were prepared by dissolving appropriate amounts of $\mathrm{NaNO}_{3}(\mathrm{~s})$ in deionized water.

Sorption Column Experiments. As in previous studies, ${ }^{14,15}$ $\mathrm{NO}_{3}{ }^{-}$was used as a nonreactive tracer to characterize the hydraulic conditions of the columns. In this case, the convectivedispersive equation can be reduced to ${ }^{19,20}$

$$
\frac{\partial C}{\partial t}=D \frac{\partial^{2} C}{\partial x^{2}}-v \frac{\partial C}{\partial x}
$$

A $100 \mathrm{mg} \cdot \mathrm{L}^{-1}$ nitrate solution was used as a tracer prior to each column experiment to determine the transport parameters of the column. The tracer was pumped through the column at the same flow rate to be used in the successive metal uptake determinations and was quantified in the outflow solution by high-performance liquid chromatography coupled with a UVdiode array detector (Waters 2695).

All column experiments were conducted in duplicate in glass columns of $72 \mathrm{~mm}$ length and $10 \mathrm{~mm}$ internal diameter (Omnifit) and uniformly packed with (1.7 to 1.8) g of grape stalks treated as explained above. During the column sorption operation at different initial concentrations, the aqueous metal solution containing (30 and 60$) \mathrm{mg} \cdot \mathrm{L}^{-1}$ of $\mathrm{Cd}(\mathrm{II})$ and $(60$ and 120$) \mathrm{mg} \cdot \mathrm{L}^{-1}$ of $\mathrm{Pb}(\mathrm{II})$ was pumped upward through the column at a constant flow rate $\left(11 \mathrm{~mL} \cdot \mathrm{h}^{-1}\right)$ and grape stalks particle size of ( 0.8 to 1.0$) \mathrm{mm}$, while the effect of the grape stalks particle size on the fixed bed sorption was performed at inlet concentration of (60 and 120$) \mathrm{mg} \cdot \mathrm{L}^{-1}$ of $\mathrm{Cd}(\mathrm{II})$ and $\mathrm{Pb}(\mathrm{II})$, respectively. Samples were collected from the outlet of the column by a fraction collector (Gilson FC204) at preset time intervals. The $\mathrm{pH}$ of the solution was measured by using a glass electrode, and the metal concentration in solution was determined by Flame Atomic Absorption Spectrometry using a Varian Absorption Spectrometer (model 1275).

Breakthrough Capacity. The sorbent is considered to be essentially exhausted when the effluent concentration, $C_{x}$ $\left(\mathrm{mg} \cdot \mathrm{L}^{-1}\right)$, reaches $90 \%$ of $C_{0}$ (initial concentration of sorbate, $\left.\mathrm{mg} \cdot \mathrm{L}^{-1}\right)$ and the breakthrough point is chosen arbitrarily at some low value, $C_{\mathrm{b}}\left(\mathrm{mg} \cdot \mathrm{L}^{-1}\right)\left(2 \%\right.$ of $C_{0}$ initial concentration of sorbate, $\left.\mathrm{mg} \cdot \mathrm{L}^{-1}\right)$. $^{21-23}$

The capacity at exhaustion $q_{\text {column }}\left(\mathrm{mg} \cdot \mathrm{g}^{-1}\right)$ is determined by calculating the total area below the breakthrough curve. This area represents the amount of solute sorbed by mass of solid in the sorption zone that goes from the breakthrough to the exhaustion point. $^{22-25}$

$$
q_{\text {column }}=\frac{\int_{V_{\mathrm{b}}}^{V_{x}}\left(C_{0}-C\right) \mathrm{d} V}{m}
$$

where $C$ is the outlet metal concentration $\left(\mathrm{mg} \cdot \mathrm{L}^{-1}\right)$ and $m$ is the mass of sorbent $(\mathrm{g})$.

The column sorption process requires prediction of the concentration-time profile or breakthrough curve for the effluent. Various mathematical models can be used to describe fixed bed sorption. One of the simplest and most widely used is the Thomas model $^{25,26}$ that allows determination of the maximum concentration of solute in the solid phase as well as the sorption rate constant. The linearized form of the model is expressed as

$$
\ln \left(\frac{C_{0}}{C}-1\right)=\frac{k_{\mathrm{Th}} q_{0} m}{Q}-\frac{k_{\mathrm{Th}} C_{0} V_{\mathrm{eff}}}{Q}
$$

where $k_{\mathrm{Th}}$ is the Thomas rate constant $\left(\mathrm{mL} \cdot \mathrm{min}^{-1} \cdot \mathrm{mg}^{-1}\right) ; q_{0}$ is the equilibrium metal uptake per gram of the sorbent $\left(\mathrm{mg} \cdot \mathrm{g}^{-1}\right) ; Q$ is the volumetric flow rate $\left(\mathrm{mL} \cdot \mathrm{min}^{-1}\right) ; V_{\text {eff }}$ is the volume of effluent (mL); and $m$ is the mass of sorbent inside the column $(\mathrm{g})$.

A linear plot of $\ln \left[\left(C_{0} / C\right)-1\right]$ against $V_{\text {eff }} / Q$ (or $t$ ) allows determination of the values of $k_{\mathrm{Th}}$ and $q_{0}$ from the intercept and the slope of the plot, respectively.

A more complex model, the two-site nonequilibrium, is also considered to characterize the overall sorption process in a fixedbed column.

Two-Site Nonequilibrium Model. The conceptual model of chemical (two-site) nonequilibrium transport ${ }^{27}$ assumes the sorption mechanism to take place in two steps, occurring either in series or in parallel. The two-site nonequilibrium concept assumes that sorption sites in sorbents can be classified into two fractions. In the first fraction, sorption is instantaneous and is described by an equilibrium sorption isotherm (Type 1, equilibrium). In the second fraction, sorption is time-dependent and follows first-order kinetics (Type 2, kinetic).

A model incorporating more than two types of sorption would be more realistic but difficult to use in the sense of practical application. Thus, the two-site model appears to be a good balance between the degree of accuracy and field applicability. For nonlinear sorption, which is assumed for both sorption domains, the governing equations for the two-site model are ${ }^{28}$

$$
\begin{gathered}
\frac{\partial C}{\partial t}+\left(\frac{\rho}{\theta}\right)\left(\frac{\partial S_{1}}{\partial t}+\frac{\partial S_{2}}{\partial t}\right)=D \frac{\partial^{2} C}{\partial x^{2}}-v \frac{\partial C}{\partial x} \\
\frac{\partial S_{2}}{\partial t}=\alpha\left[(1-F) f(C)-S_{2}\right]
\end{gathered}
$$

where $C$ is the flux average or resident concentration $\left(\mathrm{mg} \cdot \mathrm{L}^{-1}\right)$; $\rho$ is the sorbent bulk density $\left(\mathrm{kg} \cdot \mathrm{m}^{-3}\right) ; \theta$ is the volumetric water content $\left(\mathrm{m}^{3} \cdot \mathrm{m}^{-3}\right) ; t$ is time $(\mathrm{h}) ; S_{1}$ is the solid phase concentration on equilibrium sites $\left(\mathrm{mg} \cdot \mathrm{kg}^{-1}\right) ; S_{2}$ is the solid phase concentration on kinetic nonequilibrium sites $\left(\mathrm{mg} \cdot \mathrm{kg}^{-1}\right) ; D$ is the dispersion coefficient $\left(\mathrm{cm}^{2} \cdot \mathrm{h}^{-1}\right) ; x$ is distance $(\mathrm{cm}) ; v$ is the average pore water velocity $\left(\mathrm{cm} \cdot \mathrm{h}^{-1}\right) ; F$ represents the fraction of the sites available for instantaneous sorption; and $\alpha$ is a first-order rate coefficient $\left(\mathrm{h}^{-1}\right)$.

CXTFIT $^{19}$ is a program presenting a number of analytical solutions for one-dimensional transport models based on the convection-dispersion equation (CDE). It assumes steady-state 
flow in a homogeneous sorbent and first-order transformation kinetics. Both transport and sorption parameters were estimated by using the CXTFIT code under flux-type boundary conditions. ${ }^{16}$ In this case, the rate-limiting step for Type 2 sites would be either chemical (chemisorption) or diffusive intraparticle or intrasorbent diffusive mass transfer. ${ }^{19}$

According to this model, the sorbent is assumed to consist of two different types of sorption site: the sorption is instantaneous for a fraction of the sorbent (eq 3) and rate-limited for the remainder (eq 4) $)^{29-31}$

$$
\begin{gathered}
S_{1}=F f(C) \\
S_{2}=(1-F) f(C)
\end{gathered}
$$

where the subscripts 1 and 2 refer to Type- 1 and Type- 2 sites, respectively, and $C$ is the flux average or resident concentration $\left(\mathrm{mg} \cdot \mathrm{L}^{-1}\right)$; thus, total sorption, $S$, is given by $S=S_{1}+S_{2}$.

If dimensionless parameters are used, the two-site nonequilibrium model reduces to the following dimensionless form

$$
\begin{gathered}
\beta R \frac{\partial C_{1}}{\partial T}=\left(\frac{1}{P}\right)\left(\frac{\partial^{2} C_{1}}{\partial X^{2}}\right)-\frac{\partial C_{1}}{\partial X}-\omega\left(C_{1}-C_{2}\right) \\
(1-\beta) R \frac{\partial^{2} C_{2}}{\partial T}=\omega\left(C_{1}-C_{2}\right)
\end{gathered}
$$

where the subscripts 1 and 2 refer to equilibrium and nonequilibrium sites, respectively. The dimensionless parameters are defined as follows: ${ }^{19,31}$

$C_{1}$ and $C_{2}\left(\mathrm{mg} \cdot \mathrm{L}^{-1}\right)$ are the relative concentrations of metal on equilibrium and kinetic sites, respectively, with respect to the input concentration $C_{0}\left(\mathrm{mg} \cdot \mathrm{L}^{-1}\right)$, and $k_{\mathrm{L}}\left(\mathrm{m}^{3} \cdot \mathrm{kg}^{-1}\right)$ is the linear isotherm sorption coefficient

$$
\begin{gathered}
C_{1}=\frac{C}{C_{0}} \\
C_{2}=\frac{S_{2}}{\left[(1-F) k_{\mathrm{L}} C_{0}\right]}
\end{gathered}
$$

$T$ is the dimensionless time and $L$ is column length: $T=\frac{v t}{L}$

$$
\begin{gathered}
X \text { is the dimensionless distance: } X=\frac{x}{L} \\
R \text { is the retardation factor: } R=1+\frac{\rho k_{\mathrm{L}}}{\theta} \\
P \text { is the Peclet number: } P=\frac{v L}{D}
\end{gathered}
$$

$\beta$ is the fraction of instantaneous metal retardation:

$$
\beta=\frac{\left(\theta+F \rho k_{\mathrm{L}}\right)}{\left(\theta+\rho k_{\mathrm{L}}\right)}
$$

$\omega$ is a dimensionless mass transfer coefficient:

$$
\omega=\frac{\alpha(1-\beta) R L}{v}
$$

The CXTFIT code adjusts the dimensionless form of the twosite nonequilibrium model (eq 8) to the breakthrough curves to estimate the transport and sorption parameters.

\section{Results and Discussion}

Tracer Experiments. The breakthrough curve obtained for the nonreactive tracer $\left(\mathrm{NO}_{3}{ }^{-}\right)$was fitted by using eq 1 , together with the CXTFIT code. The dispersion coefficient $(D)$ and the average pore water velocity $(v)$ obtained are presented in the following sections as the physical parameters $(R=1)$. Those two parameters were kept constant for the fitting of the sorption breakthrough curves.

The pore velocity in the $\mathrm{Pb}(\mathrm{II})$ columns at (60 and 120) $\mathrm{mg} \cdot \mathrm{L}^{-1}$ inlet concentrations were $(2.3$ and 2.4$) \mathrm{cm} \cdot \mathrm{h}^{-1}$, respectively, while $\mathrm{Cd}(\mathrm{II})$ reported $(3.0$ and 2.9$) \mathrm{cm} \cdot \mathrm{h}^{-1}$ for (30 and 60$) \mathrm{mg} \cdot \mathrm{L}^{-1}$, respectively. The similarity of the pore velocities was expected since the column experiments at different inlet concentrations were performed at the same flow rate and slight differences are likely to come from differences in the packing of the columns. In the case of dispersion coefficients, the values obtained ranged from (0.6 and 1.0) $\mathrm{cm}^{2} \cdot \mathrm{h}^{-1}$ for both metals. This slight deviation is assumed to come from the heterogeneity of the sorbent material inside each column.

Effect of Initial Cd(II) and Pb(II) Concentration. An increase of the initial metal concentration when other experimental conditions are kept constant significantly affected the sorption column performance. Figure 1 shows the experimental breakthrough data for $\mathrm{Cd}(\mathrm{II})$ and $\mathrm{Pb}(\mathrm{II})$ sorption on grape stalks at different initial concentrations.

As observed, a decrease in the inlet metal concentrations gave delayed breakthrough curves, and the treated volume was also higher,since the lower concentration gradient caused slower transport due to a decreased diffusion coefficient. 9,32

Table 2 reports the breakthrough capacities calculated by eq 2 at both initial concentrations and for both metals. No significant differences were observed in the sorption capacity when the initial metal concentration was increased. When comparing both metals, a larger sorption capacity is observed for $\mathrm{Pb}$ (II) than for $\mathrm{Cd}(\mathrm{II})$. This is consistent with results obtained in previous batch experiments. ${ }^{12}$

The Thomas model was used to predict the experimental breakthrough data. Table 2 collects the Thomas model parameters obtained from slopes and intercepts of linear plots (eq 3 ). Analysis of $r^{2}$ values indicates a better fit of the Thomas model to $\mathrm{Pb}$ (II) than to $\mathrm{Cd}$ (II) sorption data. The maximum concentrations of solute on the sorbent predicted by the Thomas model are in good concordance to the sorption capacities calculated by eq 2 . The Thomas rate constant $\left(k_{\mathrm{Th}}\right)$ indicates the slope of the plots from breakthrough to exhaustion volume, thus, the volume of solution treated decreases with the increase in inlet metal concentration, indicating that the breakthrough curve becomes steeper as the inlet metal concentration increases. Figure 1 shows the modeled breakthrough curves for $\mathrm{Cd}(\mathrm{II})$ and $\mathrm{Pb}$ (II) sorption onto grape stalks at different initial concentrations. A fairly good agreement is observed between the experimental and modeled curves, indicating the applicability of the Thomas model in predicting the fixed-bed sorption of $\mathrm{Cd}(\mathrm{II})$ and $\mathrm{Pb}$ (II) onto grape stalks. 
Cd-Thomas Model
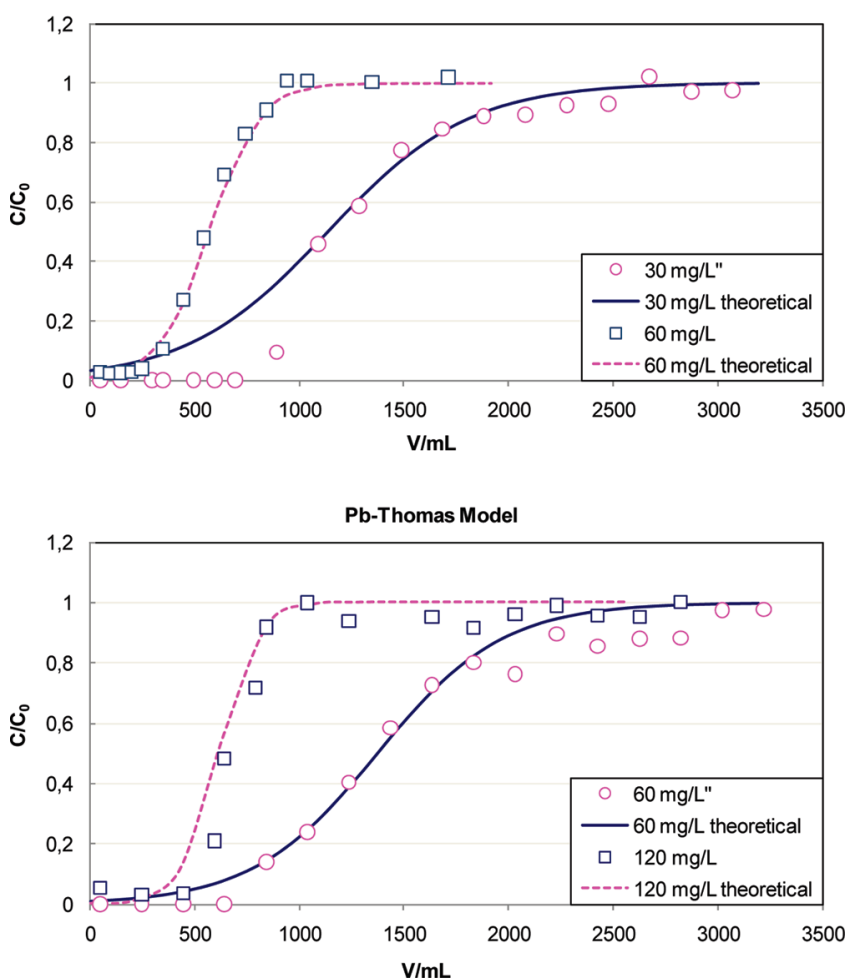

Figure 1. Measured and modeled breakthrough curves by the Thomas model for the sorption of $\mathrm{Cd}(\mathrm{II})$ and $\mathrm{Pb}$ (II) onto grape stalks $[(0.9$ to 1.0$) \mathrm{mm}$ particle size] at different initial concentrations.

Table 2. Experimental Sorption Capacities and Thomas Model Parameters for $\mathrm{Cd}(\mathrm{II})$ and $\mathrm{Pb}$ (II) Sorption onto Grape Stalks

\begin{tabular}{|c|c|c|c|c|c|}
\hline \multirow[b]{3}{*}{ metal } & \multirow[b]{2}{*}{$C_{0}$} & \multirow{2}{*}{$\frac{\frac{\text { sorption capacity }}{q_{\text {column }}}}{}$} & \multicolumn{3}{|c|}{ Thomas model } \\
\hline & & & $q_{0}$ & $k_{\mathrm{Th}}$ & \\
\hline & $\mathrm{mg} \cdot \mathrm{L}^{-1}$ & $\mathrm{mg} \cdot \mathrm{g}^{-1}$ & $\overline{\mathrm{mg} \cdot \mathrm{g}^{-1}}$ & $\mathrm{~mL} \cdot \mathrm{min}^{-1} \cdot \mathrm{mg}^{-1}$ & $r^{2}$ \\
\hline \multirow[t]{2}{*}{$\mathrm{Cd}$} & 30 & 18.76 & 18.18 & 0.022 & 0.91 \\
\hline & 60 & 17.01 & 17.14 & 0.029 & 0.98 \\
\hline \multirow[t]{2}{*}{$\mathrm{Pb}$} & 60 & 45.49 & 43.04 & 0.012 & 0.96 \\
\hline & 120 & 42.02 & 42.87 & 0.016 & 0.97 \\
\hline
\end{tabular}

The simulation of the breakthrough curves at different initial concentrations was performed by the CTXFIT code as has been detailed in the experimental section. The transport and sorption parameters obtained are reported in Table 3. In addition, Figure 2 shows the experimental breakthrough compared to the modeled values obtained by the two-site nonequilibrium sorption model. As can be seen in Figure 2, a good fit was obtained for both initial concentrations, denoting that this model describes properly both transport and sorption processes. As was expected from the breakthrough sorption capacity, the metal transport was more retarded (larger $R$ values) at lower inlet concentrations, for both metals. ${ }^{28}$ This behavior was also observed (Table 3) for the parameter $\beta$, a partition coefficient which indirectly represents the fraction of the sites available for instantaneous sorption. The linear isotherm sorption coefficients $k_{\mathrm{L}}$ were larger for lower inlet concentrations for both metals. The values of the first-order rate coefficient $\alpha$ were of the same order of magnitude for both inlet concentrations and for both metals.

As was mentioned in the Experimental Section, $\mathrm{pH}$ was monitored as a function of time. Figure 3 shows the evolution of effluent $\mathrm{pH}$ for the sorption of $\mathrm{Cd}(\mathrm{II})$ and $\mathrm{Pb}(\mathrm{II})$ at different initial concentrations. It is observed that fixed-bed operation for each metal was performed at different $\mathrm{pH}$; cadmium effluent $\mathrm{pH}$ ranged between 6.5 at the staring point and 5.8 when the column was exhausted, while 6.0 and 4.5 were the values measured for lead. In previous batch experiments, it was determined that metal removal increased with increasing solution $\mathrm{pH}$, and a maximum value was reached at an equilibrium $\mathrm{pH}$ of around 6.5 and 4.5 for $\mathrm{Cd}(\mathrm{II})$ and $\mathrm{Pb}(\mathrm{II})$, respectively, ${ }^{12}$ indicating that fixed-bed experiments were performed in the present work under suitable $\mathrm{pH}$ conditions.

Effect of the Particle Size on Cd(II) and Pb(II) Sorption. The experiments were carried out at four different grape stalk particle size ranges: [ $(0.35$ to 0.5$),(0.5$ to 0.8$),(0.8$ to 1.0$)$, and $(1.0$ to 1.4$)] \mathrm{mm}$, under constant flow rate $\left(11 \mathrm{~mL} \cdot \mathrm{h}^{-1}\right)$ and inlet concentrations of (60 and 120$) \mathrm{mg} \cdot \mathrm{L}^{-1}$ for $\mathrm{Cd}(\mathrm{II})$ and $\mathrm{Pb}(\mathrm{II})$, respectively.

It is well-known that, generally speaking, the performance of sorption is improved by decreasing the particle size; however, small particle sizes can result in high flow resistance of the column which should be avoided. ${ }^{9}$ Figure 4 shows the influence of particle sizes on metal sorption. It can be seen that the behavior observed for the particle sizes larger than $0.8 \mathrm{~mm}$ was as expected. However, the breakthrough curves for the particle sizes $(0.35$ to 0.5$) \mathrm{mm}$ and $(0.5$ to 0.8$) \mathrm{mm}$ reported similar behavior, and no significant difference was observed for $\mathrm{Cd}(\mathrm{II})$. Besides, in the case of $\mathrm{Pb}(\mathrm{II})$, the particle size $(0.5$ to 0.8$) \mathrm{mm}$ gave a better sorption performance than $(0.35$ to 0.5$) \mathrm{mm}$.

This behavior can be explained assuming that the voidages of the sorption beds are reduced for the small particle size ranges. ${ }^{33} \mathrm{~A}$ larger particle (higher than $0.5 \mathrm{~mm}$ ) may give, on the contrary, high interparticle voidage. Hence, for the same mass of sorbent, the column packed with the larger sorbent particle size range gives a longer bed column than the one packed with smaller diameter sorbent particles.

For the particle size range of $(0.5$ to 0.8$) \mathrm{mm}$, sorption breakthrough curves followed a much more efficient profile than for larger particle size ranges: the breakthrough time increased, and the curves tended toward the classic " $\mathrm{S}$ " shape profile. ${ }^{34}$

Table 4 collects the sorption capacities calculated for both metals by using eq 2 and the Thomas model parameters obtained from slopes and intercepts of linear plots at different particle sizes. It was observed that both metals reported the same behavior, thus the maximum sorption capacity was obtained at the particle size of $(0.5$ to 0.8$) \mathrm{mm}$, closely followed for the particle size $(0.35$ to 0.5$) \mathrm{mm}$; for larger particle size, the basic trend was that the sorption capacities decreased with increasing particle size.

As can be observed in Figure 4, the Thomas model fits properly the sorption of $\mathrm{Cd}$ (II) and $\mathrm{Pb}$ (II) onto grape stalks at different particle sizes. This is shown in Table 4, which collects the Thomas model parameters obtained by linear analysis. As observed, the maximum concentration of solute on the sorbent predicted by the Thomas model follows the same trend of the sorption capacity calculated by eq 2 .

The two-site nonequilibrium model was used to describe the breakthrough experimental data at different particle sizes for the sorption of $\mathrm{Cd}(\mathrm{II})$ and $\mathrm{Pb}(\mathrm{II})$ onto grape stalks. Figure 5 shows the experimental and the predicted curves, and Table 5 collects the transport and sorption parameters obtained by fitting the experimental breakthrough curves to the two-site nonequilibrium model. As can be observed in Figure 5, the agreement between the experimental and predicted breakthrough curves is good for both metals, indicating that the two-site model can properly describe the sorption of $\mathrm{Cd}(\mathrm{II})$ and $\mathrm{Pb}$ (II) onto grape stalks in fixed-bed columns.

As was expected from the breakthrough sorption capacity, the metal transport was more retarded (large $R$ values) at the 
Table 3. Physical Parameters Obtained by Fitting the Equilibrium CDE to the Breakthrough of $\mathrm{NO}_{3}{ }^{-}$Tracer $(R=1)$ and Model Parameters Obtained by Fitting $\mathrm{Cd}(\mathrm{II})$ and $\mathrm{Pb}$ (II) Experimental Breakthrough Data to the Nonequilibrium Sorption Model ${ }^{a}$

\begin{tabular}{|c|c|c|c|c|c|c|c|c|c|c|}
\hline \multirow[b]{2}{*}{ metal } & \multirow[b]{2}{*}{$C_{0}$} & \multicolumn{3}{|c|}{ physical parameters $(R=1)$} & \multicolumn{6}{|c|}{ two-site sorption model parameters } \\
\hline & & $D$ & $v$ & $r^{2}$ & $R$ & $\beta$ & $\omega$ & $r^{2}$ & $k_{\mathrm{L}}$ & $\alpha$ \\
\hline \multirow[t]{2}{*}{$\mathrm{Cd}$} & 30 & 0.8 & 3.0 & 0.994 & 64.0 & 0.87 & 0.015 & 0.994 & 0.050 & $9.0 \cdot 10^{-4}$ \\
\hline & 60 & 1.0 & 2.9 & 0.996 & 25.7 & 0.82 & 0.010 & 0.995 & 0.020 & $1.1 \cdot 10^{-3}$ \\
\hline $\mathrm{Pb}$ & 120 & 0.6 & 2.4 & 0.970 & 28.0 & 0.80 & 0.032 & 0.972 & 0.021 & $5.0 \cdot 10^{-3}$ \\
\hline
\end{tabular}

${ }^{a} C_{0} / \mathrm{mg} \cdot \mathrm{L}^{-1} ; D / \mathrm{cm}^{2} \cdot \mathrm{h}^{-1} ; v / \mathrm{cm} \cdot \mathrm{h}^{-1} ; k_{\mathrm{L}} / \mathrm{m}^{3} \cdot \mathrm{kg}^{-1} ; \alpha / \mathrm{h}^{-1}$.

\section{Cd-Two-site nonequilibrium model}

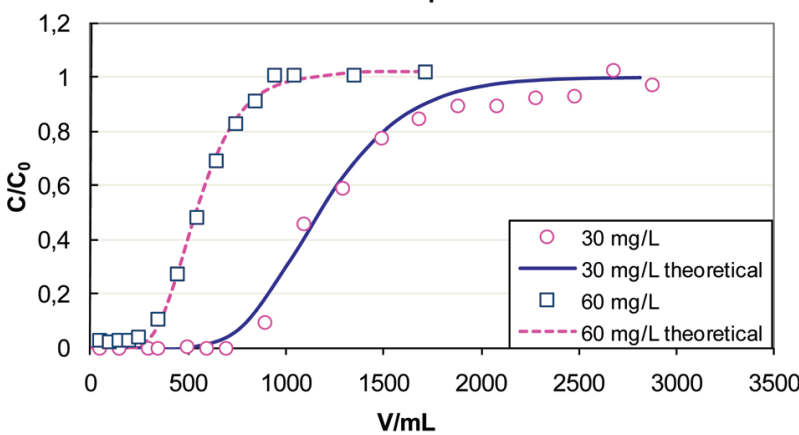

Pb-Two-site nonequilibrium model

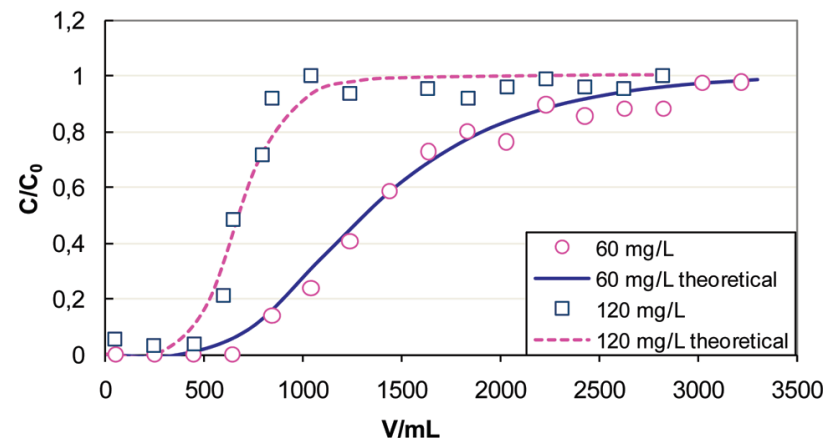

Figure 2. Measured and modeled breakthrough curves by the two-site nonequilibrium model for the sorption of $\mathrm{Cd}(\mathrm{II})$ and $\mathrm{Pb}(\mathrm{II})$ onto grape stalks [(0.9 to 1.0$) \mathrm{mm}$ particle size] at different initial concentration.

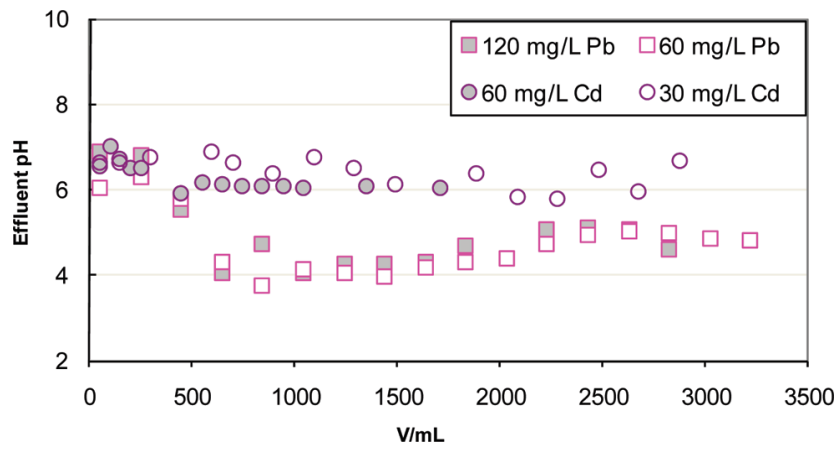

Figure 3. Measured effluent $\mathrm{pH}$ for the sorption of $\mathrm{Cd}(\mathrm{II})$ and $\mathrm{Pb}$ (II) onto grape stalks [ $(0.9$ to 1.0$) \mathrm{mm}$ particle size] at different initial concentration.

particle sizes of $(0.5$ to 0.8$) \mathrm{mm}$ (Table 5$)$. This behavior was also observed for the partition coefficient $\beta$ as well as for the linear isotherm sorption coefficients $k_{\mathrm{L}}$. However, these parameters were similar to those reported at the particle size $(0.35$ to $0.5) \mathrm{mm}$, indicating that sorption performance was very close for both particle sizes, while for larger particle sizes the basic trend was the one previously observed at the sorption capacity calculations.
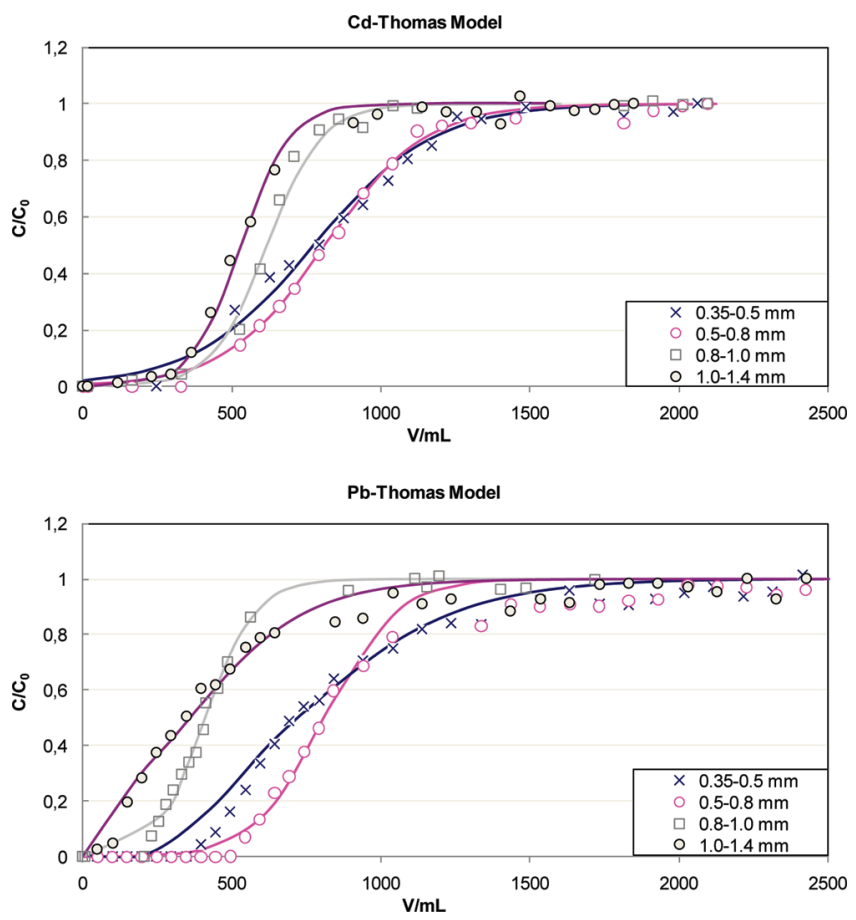

Figure 4. Measured and modeled (solid line) breakthrough curves by the Thomas model for the sorption of $\mathrm{Cd}(\mathrm{II})$ and $\mathrm{Pb}$ (II) [(60 and 120$) \mathrm{mg} \cdot \mathrm{L}^{-1}$, respectively] onto grape stalks at different particle sizes.

Table 4. Effect of the Particle Size on the Breakthrough Capacity and Thomas Model Parameters for $\mathrm{Cd}$ (II) and $\mathrm{Pb}$ (II) Sorption onto Grape Stalks

\begin{tabular}{|c|c|c|c|c|c|}
\hline \multirow[b]{3}{*}{ metal } & \multirow[b]{2}{*}{ particle size } & \multirow{2}{*}{$\frac{\frac{\text { sorption capacity }}{q_{\text {column }}}}{}$} & \multicolumn{3}{|c|}{ Thomas model } \\
\hline & & & $q_{0}$ & $k_{\mathrm{Th}}$ & \\
\hline & $(\mathrm{mm})$ & $\mathrm{mg} \cdot \mathrm{g}^{-1}$ & $\mathrm{mg} \cdot \mathrm{g}^{-1}$ & $\mathrm{~mL} \cdot \mathrm{min}^{-1} \cdot \mathrm{mg}^{-1}$ & $r^{2}$ \\
\hline \multirow[t]{4}{*}{$\mathrm{Cd}$} & 0.35 to 0.5 & 31.73 & 28.57 & 0.014 & 0.99 \\
\hline & 0.5 to 0.8 & 33.12 & 31.53 & 0.016 & 0.99 \\
\hline & 0.8 to 1.0 & 20.90 & 22.20 & 0.032 & 0.93 \\
\hline & 1.0 to 1.4 & 20.47 & 19.23 & 0.035 & 0.98 \\
\hline \multirow[t]{4}{*}{$\mathrm{Pb}$} & 0.35 to 0.5 & 55.18 & 48.93 & 0.006 & 0.94 \\
\hline & 0.5 to 0.8 & 56.11 & 49.40 & 0.014 & 0.97 \\
\hline & 0.8 to 1.0 & 39.01 & 38.51 & 0.015 & 0.99 \\
\hline & 1.0 to 1.4 & 33.56 & 25.25 & 0.007 & 0.95 \\
\hline
\end{tabular}

In Table 5, it is shown that both metals follow the same behavior, and the differences reported between parameters obtained for $\mathrm{Cd}(\mathrm{II})$ and $\mathrm{Pb}$ (II) were in concordance to those previously observed in the sorption capacity (Table 4).

Batch experiments performed in a previous study reported maximum sorbent capacities determined by the Langmuir isotherm model. ${ }^{12}$ The values reported in that work for cadmium and lead onto grape stalk wastes were $(27.9$ and 49.9$) \mathrm{mg} \cdot \mathrm{g}^{-1}$ for $\mathrm{Cd}(\mathrm{II})$ and $\mathrm{Pb}(\mathrm{II})$, respectively. Considering the different methodologies, a comparison can be made from a purely academic point of view. Thus, comparing the sorption capacity at two inlet concentrations and at different particle sizes for 
Cd-Two-site nonequilibrium model

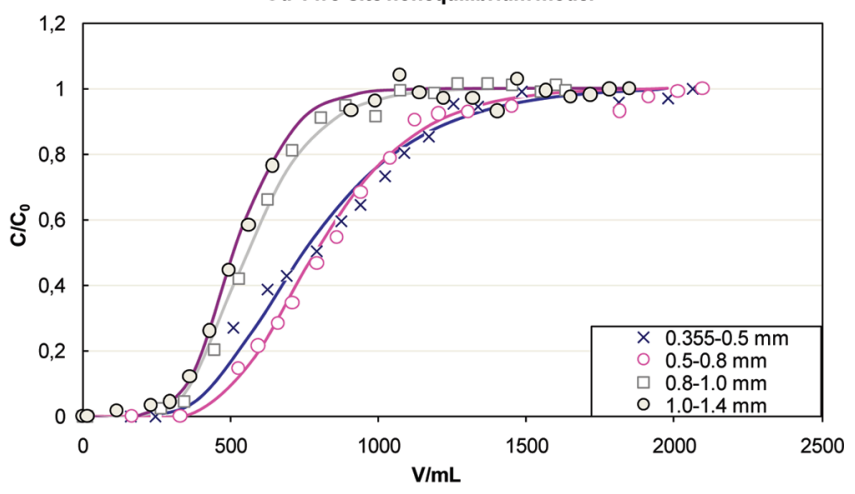

$\mathrm{Pb}-\mathrm{T}$ wo-site nonequilibrium model

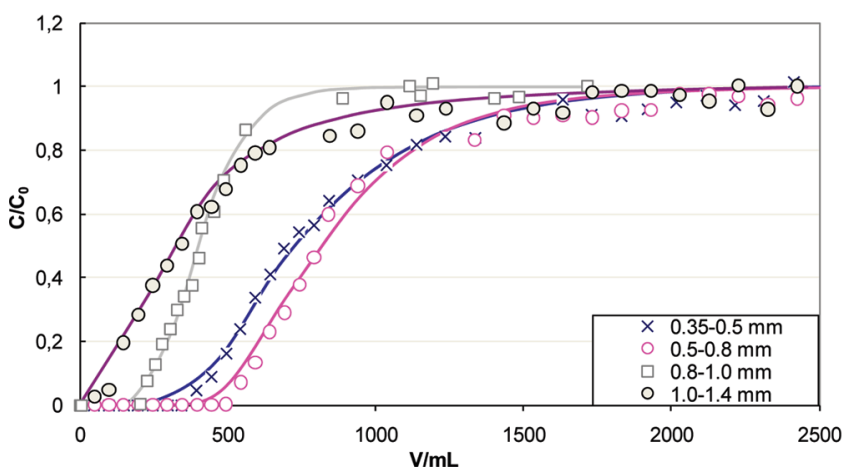

Figure 5. Measured and modeled (solid line) breakthrough curves by the two-site nonequilibrium model for the sorption of $\mathrm{Cd}(\mathrm{II})$ and $\mathrm{Pb}$ (II) [(60 and 120) $\mathrm{mg} \cdot \mathrm{L}^{-1}$, respectively] onto grape stalks at different particle sizes.

both metals (Table 2 and 4), it is concluded that sorption capacities at batch and fixed-bed column are of the same order of magnitude for both metals.

From the literature reviewed, the sorbents used in different studies can be compared in terms of maximum sorption capacities obtained for sorption of $\mathrm{Cd}$ (II) and $\mathrm{Pb}$ (II) ions from aqueous solution in a fixed-bed column (Table 6). It can be stated that grape stalk wastes in this study reported reasonable sorption capacities in comparison to other sorbents, with the additional advantage to be abundant and economic.

\section{Conclusions}

The results show that grape stalk waste can be employed as a sorbent for the removal of $\mathrm{Cd}$ (II) and $\mathrm{Pb}$ (II) from aqueous solutions in column experiments. The sorption capacity depends on the inlet metal ion concentration: at the highest metal concentration, the grape stalk column saturated
Table 6. Comparison of the Sorption Capacity Obtained for Cd(II) and $\mathrm{Pb}$ (II) Removal onto Grape Stalks and Other Types of Sorbents in a Fixed Bed Column

\begin{tabular}{|c|c|c|c|}
\hline sorbent & metal & $\frac{q}{\mathrm{mg} \cdot \mathrm{g}^{-1}}$ & ref \\
\hline Amberlite IRC-718 chelating resin & $\mathrm{Pb}$ & 19.9 & 35 \\
\hline Chelex-100 & $\mathrm{Pb}$ & 22.8 & 35 \\
\hline coir fibres & $\mathrm{Pb}$ & 16.6 & 36 \\
\hline dye loaded coir fibres & $\mathrm{Pb}$ & 19.6 & 36 \\
\hline manganese oxide coated zeolite & $\mathrm{Pb}$ & 58.2 & 37 \\
\hline tea waste & $\mathrm{Pb}$ & 46 & 38 \\
\hline granular activated carbon & $\mathrm{Pb}$ & 19 & 38 \\
\hline $\begin{array}{l}\text { carbonaceous material (pyrolyzed } \\
\text { sewage sludge) }\end{array}$ & $\mathrm{Pb}$ & 9.1 & 6 \\
\hline grape stalk wastes & $\mathrm{Pb}$ & 56.11 & this work \\
\hline Amberlite IRC-718 chelating resin & $\mathrm{Cd}$ & 119.1 & 35 \\
\hline Chelex-100 & $\mathrm{Cd}$ & 112.4 & 35 \\
\hline highly mineralized peat & $\mathrm{Cd}$ & 41.4 & 39 \\
\hline plain chitosan & $\mathrm{Cd}$ & 40.1 & 2 \\
\hline $\begin{array}{l}\text { carbonaceous material (pyrolyzed } \\
\text { sewage sludge) }\end{array}$ & $\mathrm{Cd}$ & 22.9 & 6 \\
\hline sphagnum peat moss & $\mathrm{Cd}$ & 1.91 & 40 \\
\hline mollusk shells & $\mathrm{Cd}$ & 8.15 & 40 \\
\hline grape stalk wastes & $\mathrm{Cd}$ & 33.12 & this work \\
\hline
\end{tabular}

quickly leading to earlier breakthrough and exhaustion time. The Thomas model was used to predict the experimental breakthrough data, giving a good agreement between experimental and modeled curves. The maximum solid phase concentration of solute on the sorbent predicted by the Thomas model was in concordance to the sorption capacity calculated by experimental data, indicating the applicability of this model in predicting the fixed-bed sorption of metals onto grape stalks.

The experimental breakthrough curves can be properly described by the convective-dispersive equation (CDE) and the two-site deterministic nonequilibrium (TSM/CDE) model by using the CXTFIT code. A good agreement between the predicted and experimental breakthrough values was observed. The sorption parameters obtained by the two-site nonequilibrium model were influenced by the inlet metal concentration and by the particle sizes.

The same behavior was observed for both metals, thus the maximum sorption capacity and higher sorption and transport parameters were obtained at the particle size of (0.5 to 0.8 ) $\mathrm{mm}$, closely followed by the particle size $(0.35$ to 0.5$) \mathrm{mm}$; for larger particle sizes, the basic trend was that the sorption capacity and transport parameters decreased with increasing particle size.

\section{Acknowledgment}

We are extremely grateful to Carme Gauchia for analysis of the samples and Mónica Arnaiz for laboratory help in the sorption experiments.

Table 5. Effect of the Particle Size on Physical Parameters Obtained by Fitting the Equilibrium $\mathrm{CDE}$ to the $\mathrm{Breakthrough}^{-} \mathrm{NO}_{3}{ }^{-} \mathrm{Tracer}(R$ $=1$ ) and Model Parameters Obtained by Fitting $\mathrm{Cd}(\mathrm{II})$ and $\mathrm{Pb}(\mathrm{II})$ Experimental Breakthrough Data to the Nonequilibrium Sorption Model ${ }^{a}$

\begin{tabular}{|c|c|c|c|c|c|c|c|c|c|c|}
\hline \multirow[b]{2}{*}{ metal } & \multirow[b]{2}{*}{ particle size $(\mathrm{mm})$} & \multicolumn{3}{|c|}{ physical parameters $(R=1)$} & \multicolumn{6}{|c|}{ two-site sorption model parameters } \\
\hline & & $D$ & $v$ & $r^{2}$ & $R$ & $\beta$ & $\omega$ & $r^{2}$ & $k_{\mathrm{L}}$ & $\alpha$ \\
\hline \multirow[t]{4}{*}{$\mathrm{Cd}$} & 0.35 to 0.5 & 2.5 & 3.5 & 0.988 & 51.3 & 0.87 & 0.015 & 0.985 & 0.040 & $1.3 \cdot 10^{-3}$ \\
\hline & 0.5 to 0.8 & 1.3 & 3.3 & 0.995 & 52.9 & 0.86 & 0.015 & 0.995 & 0.041 & $1.1 \cdot 10^{-3}$ \\
\hline & 0.8 to 1.0 & 1.0 & 2.6 & 0.998 & 26.8 & 0.85 & 0.010 & 0.995 & 0.020 & $1.1 \cdot 10^{-3}$ \\
\hline & 1.0 to 1.4 & 0.7 & 2.6 & 0.994 & 24.9 & 0.82 & 0.006 & 0.994 & 0.019 & $5.9 \cdot 10^{-4}$ \\
\hline \multirow[t]{4}{*}{$\mathrm{Pb}$} & 0.35 to 0.5 & 4.1 & 5.5 & 0.983 & 75.1 & 0.89 & 0.033 & 0.990 & 0.058 & $3.7 \cdot 10^{-3}$ \\
\hline & 0.5 to 0.8 & 2.2 & 5.9 & 0.980 & 86.0 & 0.89 & 0.066 & 0.988 & 0.067 & $7.2 \cdot 10^{-3}$ \\
\hline & 0.8 to 1.0 & 1.3 & 3.9 & 0.978 & 29.8 & 0.83 & 0.009 & 0.984 & 0.023 & $1.2 \cdot 10^{-3}$ \\
\hline & 1.0 to 1.4 & 2.4 & 2.8 & 0.967 & 24.3 & 0.80 & 0.008 & 0.980 & 0.018 & $7.6 \cdot 10^{-4}$ \\
\hline
\end{tabular}

${ }^{a} \mathrm{D} / \mathrm{cm}^{2} \cdot \mathrm{h}^{-1} ; \nu / \mathrm{cm} \cdot \mathrm{h}^{-1} ; k_{\mathrm{L}} / \mathrm{m}^{3} \cdot \mathrm{kg}^{-1} ; \alpha / \mathrm{h}^{-1}$. 


\section{Literature Cited}

(1) Kadirvelu, K.; Goel, J.; Rajagopal, C. Sorption of lead, mercury and cadmium ions in multi-component system using carbon aerogel as adsorbent. J. Hazard. Mater. 2008, 153, 502-507.

(2) Sankararamakrishnan, N.; Kumar, P.; Chauhan, V. S. Modeling fixed bed column for cadmium removal from electroplating wastewater. Sep. Purif. Technol. 2008, 63, 213-219.

(3) Turan, M.; Mart, U.; Yüksel, B.; Celik, M. S. Lead removal in fixed-bed columns by zeolite and sepiolite. Chemosphere 2005, 60, 1487-1492.

(4) Medvidovic, N. V.; Peric, J.; Trgo, M. Column performance in lead removal from aqueous solutions by fixed bed of natural zeoliteclinoptilolite. Sep. Purif. Technol. 2006, 49, 237-244.

(5) Febrianto, J.; Kosasih, A. N.; Sunarso, J.; Ju, Y.-H.; Indraswati, N.; Ismadji, S. Equilibrium and kinetic studies in adsorption of heavy metals using biosorbent: A summary of recent studies. J. Hazard. Mater. 2009, 162, 616-645.

(6) Gutiérrez-Segura, E.; Colín-Cruz, A.; Fall, C.; Solache-Ríos, M.; BalderasHernández, $\mathrm{P}$. Comparison of $\mathrm{Cd}-\mathrm{Pb}$ adsorption on commercial activated carbon and carbonaceous material from pyrolysed sewage sludge in column system. Environ. Technol. 2009, 30, 455-461.

(7) Gupta, V. K. Equilibrium Uptake, Sorption Dynamics, Process Development, and Column Operations for the Removal of Copper and Nickel from Aqueous Solution and Wastewater Using Activated Slag, a Low-Cost Adsorbent. Ind. Eng. Chem. Res. 1998, 37, 192-202.

(8) Fiol, N.; Villaescusa, I.; Martínez, M.; Miralles, N.; Poch, J.; Serarols, $\mathrm{J}$. Sorption of $\mathrm{Pb}(\mathrm{II}), \mathrm{Ni}(\mathrm{II}), \mathrm{Cu}(\mathrm{II})$, and $\mathrm{Cd}(\mathrm{II})$ from aqueous solutions by olive stone waste. Sep. Purif. Technol. 2006, 50, 132-140.

(9) Malkoc, E.; Nuhoglu, Y. Removal of Ni(II) ions from aqueous solutions using waste of tea factory: Adsorption on a fixed-bed column J. Hazard. Mater. 2006, 135, 328-336.

(10) Villaescusa, I.; Fiol, N.; Martínez, M.; Miralles, N.; Poch, J.; Serarols, J. Removal of copper and nickel ions from aqueous solutions by grape stalks wastes. Water Res. 2004, 38, 992-1002.

(11) Escudero, C.; Gabaldón, C.; Marzal, P.; Villaescusa, I. Effect of EDTA on divalent metal adsorption onto grape stalk and exhausted coffee wastes. J. Hazard. Mater. 2008, 152, 476-485.

(12) Martinez, M.; Miralles, N.; Hidalgo, S.; Fiol, N.; Villaescusa, I.; Poch, J. Removal of lead(II) and cadmium(II) from aqueous solutions using grape stalk waste. J. Hard. Mater. 2006, 122, 203-211.

(13) Fiol, N.; Escudero, C.; Villaescusa, I. Chromium sorption and $\mathrm{Cr}(\mathrm{VI})$ reduction to $\mathrm{Cr}(\mathrm{III})$ by grape stalks and yohimbe bark. Bioresour. Technol. 2008, 99, 5030-5036.

(14) Valderrama, C.; Arévalo, J. A.; Casas, I.; Martínez, M.; Miralles, N.; Florido, A. Modelling of the Ni(II) removal from aqueous solutions onto grape stalk wastes in fixed-bed column. J. Hazard. Mater. 2010 174, 144-150.

(15) Florido, A.; Valderrama, C.; Arévalo, J. A.; Casas, I.; Martínez, M.; Miralles, N. Application of two sites non-equilibrium sorption model for the removal of $\mathrm{Cu}$ (II) onto grape stalk wastes in a fixed-bed column. Chem. Eng. J. 2010, 156, 298-304

(16) B Fonseca, B.; Teixeira, A.; Figueiredo, H.; Tavares, T. Modelling of the $\mathrm{Cr}(\mathrm{VI})$ transport in typical soils of the North of Portugal. J. Hazard. Mater. 2009, 167, 756-762.

(17) Wang, T.-H.; Li, M.-H.; Teng, S.-P. Bridging the gap between batch and column experiments: A case study of Cs adsorption on granite. $J$. Hazard. Mater. 2009, 161, 409-415.

(18) Chu, K. H. Improved fixed bed models for metal biosorption. Chem. Eng. J. 2004, 97, 233-239.

(19) Toride, N., Leij, F. J., van Genuchten, M. T. The CXTFIT code for estimating transport parameters from laboratory or field tracer experiments; U.S. Salinity Laboratory, U.S. Department of Agriculture: Riverside, CA, 1995; p 137.

(20) van Genuchten, M. T. A closed-form equation for predicting the hydraulic conductivity of unsaturated soils. Soil Sci. Soc. Am. J. 1980, $44,892-898$.

(21) Gupta, V. K.; Srivastava, S. K.; Mohan, D. Equilibrium Uptake, Sorption Dynamics, Process Optimization, and Column Operations for the Removal and Recovery of Malachite Green from Wastewater
Using Activated Carbon and Activated Slag. Ind. Eng. Chem. Res. 1997, 36, 2207-2218.

(22) Gupta, V. K.; Srivastava, S. K.; Tyagi, R. Design parameters for the treatment of phenolic wastes by carbon columns (obtained from fertilizer waste material). Water Res. 2000, 34, 1543-1550.

(23) Goud, V. V.; Mohanty, K.; Rao, M. S.; Jayakumar, N. S. Prediction of Mass Transfer Coefficients in a packed bed using Tamarind Nut Shell Activated Carbon to remove Phenol. Chem. Eng. Technol. 2005, 28, 991-997.

(24) Al-Degs, Y. S.; Khraisheh, M. A. M.; Allen, S. J.; Ahmad, M. N. Adsorption characteristics of reactive dyes in columns of activated carbon. J. Hazard. Mater. 2009, 165, 944-949.

(25) Vijayaraghavan, K.; Jegan, J.; Palanivelu, K.; Velan, M. Biosorption of copper, cobalt and nickel by marine green alga Ulva reticulata in a packed column. Chemosphere 2005, 60, 419-426.

(26) Yin, C. Y.; Aroua, M. K.; Daud, W. M. A. Fixed-bed adsorption of metal ions from aqueous solution on polyethyleneimine-impregnated palm shell activated carbon. Chem. Eng. J. 2009, 148, 8-14.

(27) Cameron, D. R.; Klute, A. Convective-dispersive solute transport with a combined equilibrium and kinetic adsorption model. Water Resour. Res. 1997, 13, 183-188.

(28) Tsang, D. C. W.; Zhang, W.; Lo, I. M. C. Modeling Cadmium Transport in Soils Using Sequential Extraction, Batch, and Miscible Displacement Experiments. Soil Sci. Soc. Am. J. 2007, 71, 674-681.

(29) Bajracharya, K.; Barry, D. A. MCMFIT-efficient optimal fitting of a generalized nonlinear advection-dispersion model to experimental-data. Comput. Geosci. 1995, 21, 61-76.

(30) Kamra, S. K.; Lennartz, B.; Van Genuchten, M. T.; Widmoser, P. Evaluating non-equilibrium solute transport in small soil columns. $J$. Contam. Hydrol. 2001, 48, 189-212.

(31) van Genuchten, M. T.; Wagenet, R. J. Two-Site/Two-Region Models for Pesticide Transport and Degradation: Theoretical Development and Analytical Solutions. Soil Sci. Soc. Am. J. 1989, 53, 1303-1310.

(32) Padmesh, T. V. N.; Vijayaraghavan, K.; Sekaran, G.; Velan, M. Batch and column studies on biosorption of acid dyes on fresh water macro alga Azolla filiculoides. J. Hazard. Mater. 2005, 125, 121-129.

(33) Lee, V. K. C.; Porter, J. F.; McKay, G. Development of Fixed-Bed Adsorber Correlation Models. Ind. Eng. Chem. Res. 2000, 39, 2427-2433.

(34) Rivero, M. J.; Ibanez, R.; Ortiz, I. M. Mathematical modelling of styrene drying by adsorption onto activated alumina. Chem. Eng. Sci. 2002, 57, 2589-2592.

(35) Malla, M.; Alvarez, M. B.; Batistoni, D. A. Evaluation of sorption and desorption characteristics of cadmium, lead and zinc on Amberlite IRC-718 iminodiacetate chelating ion exchanger. Talanta 2002, 57, 277-287.

(36) Shukla, S. R.; Pai, R. S. Comparison of $\mathrm{Pb}$ (II) uptake by coir and dye loaded coir fibres in a fixed bed column. J. Hazard. Mater. 2005, 125 , $147-153$.

(37) Han, R.; Zou, w.; Li, h.; Li, y.; Shi, J. Copper(II) and lead(II) removal from aqueous solution in fixed-bed columns by manganese oxide coated zeolite. J. Hazard. Mater 2006, 137, 934-942.

(38) Amarasinghe, B. M. W. P. K.; Williams, R. A. Tea waste as a low cost adsorbent for the removal of $\mathrm{Cu}$ and $\mathrm{Pb}$ from wastewater. Chem. Eng. J. 2007, 132, 299-309.

(39) Gabaldón, C.; Marzal, P.; Alvarez-Hornos, F. J. Modelling Cd(II) removal from aqueous solutions by adsorption on a highly mineralized peat. Batch and fixed-bed column experiments. J. Chem. Technol. Biotechnol. 2006, 81, 1107-1112.

(40) Li, C.; Champagne, P. Fixed-bed column study for the removal of cadmium (II) and nickel (II) ions from aqueous solutions using peat and mollusk shells. J. Hazard. Mater. 2009, 171, 872-878.

Received for review March 2, 2010. Accepted July 24, 2010. We wish to acknowledge the contribution of the MICINN project CTM200806776-C02-02/TECNO (Spanish Ministry of Science and Innovation).

\section{JE100200W}

